
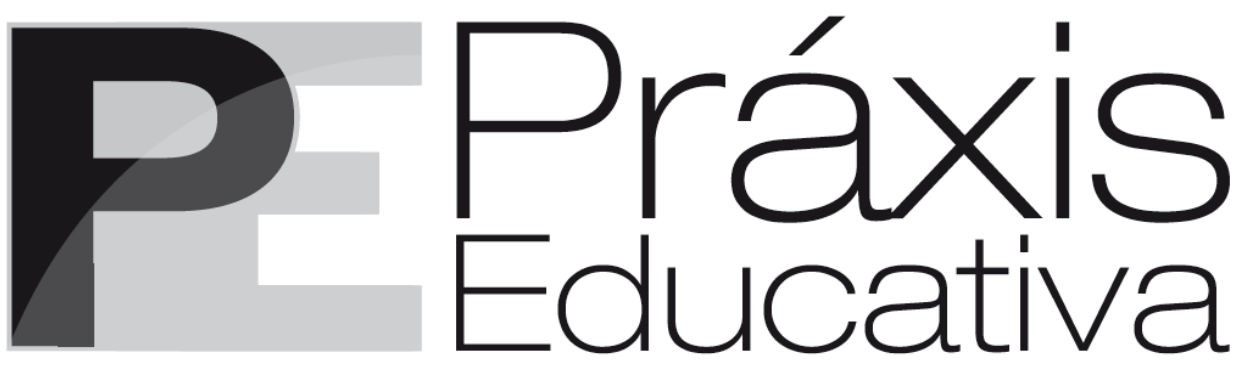

ISSN 1809-4309 (Versão online)

DOI: 10.5212/PraxEduc.v.11i3.0017

\title{
A avaliação na Educação Infantil: uma análise a partir de relatórios de uma \\ professora
}

\section{Evaluation in pre-school: an analysis based on a teacher's reports}

\section{La evaluación en la enseñanza infantil: un análisis a partir de informes de \\ una maestra}

\author{
Gabriela Medeiros Nogueira* \\ Gabriela Ortiz Prado**
}

\begin{abstract}
Resumo: Este trabalho apresenta resultados de uma pesquisa que teve por objetivo compreender como uma professora de Escola Municipal - Educação Infantil em Rio Grande (RS) concebe a avaliação nesta etapa da Educação Básica. A pesquisa foi realizada por meio de análise documental e teve como corpus, dezesseis "Relatórios de avaliação" elaborados em 2014. A análise dos dados deu-se a partir dos estudos de Barbosa (2006; 2008); Hoffmann (2003, 2011, 2014), Bondioli (2004), Guimarães e Oliveira (2014). Os resultados indicam uma perspectiva de avaliação mais focada no trabalho do professor do que nas crianças, evidenciando propostas e resultados, sem enfatizar o percurso. Todos os relatórios analisados apresentam sistematicamente a mesma estrutura e organização textual, independentemente da criança que esteja sendo avaliada. Conclui-se, desse modo, que as particularidades de cada criança são desconsideradas nos relatórios, uma vez que todas podem ser descritas por meio de uma mesma frase.
\end{abstract}

Palavras-chave: Avaliação. Educação Infantil. Relatórios de avaliação.

Abstract: This paper presents the results of a study that aimed to understand how a teacher from a municipal pre-school school in Rio Grande (RS) saw evaluation in this phase of basic education. The research was carried out through document analysis whose corpus comprised "Evaluation Reports" written in 2014. The data analysis was supported by the studies of Barbosa (2006; 2008); Hoffmann (2003, 2011, 2014), Bondioli (2004), Guimarães and Oliveira (2014). The results indicated an evaluation perspective focused on the teachers' work rather than on the children, highlighting proposals and results, without emphasizing the trajectory. All the reports analyzed presented systematically the same structure and text organization, regardless of the children being evaluated. The conclusion, therefore, was that the particularities of each child were neglected in the reports, since all of them could be described by using the same sentence.

Keywords: Evaluation. Pre-school. Evaluation reports.

Resumen: El trabajo presenta los resultados de una pesquisa que ha tenido por objetivo comprender como una maestra de una Escuela Municipal de Enseñanza Infantil en Rio Grande (RS) concibe la

\footnotetext{
* Professora da Universidade Federal do Rio Grande (FURG). E-mail: <gabynogueira@me.com>.

** Professora da Rede Municipal de Ensino de Rio Grande - RS. E-mail: <gabillp@hotmail.com>.
} 
evaluación en esta etapa da Enseñanza Básica. La pesquisa ha sido realizada con un análisis documental ha tenido como corpus dieciséis "Informes de evaluación" elaborados en 2014. El análisis de los datos se ha dado por estudios con Barbosa (2006; 2008); Hoffmann (2003, 2011, 2014), Bondioli (2004), Guimarães y Oliveira (2014). Los resultados indican una perspectiva de evaluación con más enfoque en el trabajo del maestro que en los niños, poniendo en evidencia propuestas y resultados, sin énfasis en el trayecto. Todos los informes analizados presentan sistemáticamente la misma estructura y organización textual, independientemente del niño que sea evaluado. Se concluyó, de ese modo, que las particularidades de cada niño son desconsideradas en los informes, así que todos pueden ser descritos por medio de una misma frase.

Palabras clave: Evaluación. Enseñanza Infantil. Informes de evaluación.

\section{Introdução}

Este trabalho apresenta resultados de uma pesquisa sobre avaliação na Educação Infantil, realizada em 2014, que teve por objetivo compreender como uma professora de Escola Municipal - Educação Infantil em Rio Grande (RS) concebe a avaliação nesta etapa da Educação Básica.

Partimos do entendimento de que a avaliação realizada na educação escolar, e também na Educação Infantil, condiz com a visão pedagógica do docente e da instituição que a propõem (HADJI, 2001), traduzindo: de forma consciente - ou não - trata-se dos conceitos de educação, criança, infância e aprendizagem que escola e professor concebem. A avaliação engloba as concepções e práticas construídas pelas trajetórias e pela formação dos professores, envolvendo o desenvolvimento e a aprendizagem das crianças (linguagens, habilidades) e articulando todos esses fatores ao planejamento do professor (organização da rotina, espaço, tempo e propostas). A perspectiva que fundamenta este trabalho, portanto, é de uma avaliação processual e de acompanhamento da criança, em que a prática pedagógica e as concepções dos professores permeiam esse processo.

Com o intuito de compreender o contexto legal que envolve a avaliação na Educação Infantil tratamos, na primeira seção deste artigo, sobre as orientações presentes em documentos oficiais, mais especificamente nas Diretrizes Curriculares Nacionais para Educação Infantil (2010), bem como, explicitamos o destaque e as polêmicas relativas a este tema que emergem das propostas e ações de avaliação externa para esta etapa.

$\mathrm{Na}$ segunda seção, apresentamos algumas perspectivas teóricas de pesquisadores da área da educação como Hoffmann (2003; 2004; 2012), Esteban (2004), Bondioli (2004), Barbosa (2008) e Hadji (2001), que discutem a avaliação e a apontam como um tema que precisa ser discutido e refletido, por se configurar como uma das questões mais desafiadoras para os profissionais da área.

$\mathrm{Na}$ terceira e na quarta seção, apresentamos a análise dos relatórios de avaliação, de grupo e individuais, ou seja, dos documentos produzidos no processo de avaliação, pela professora participante da pesquisa, ao longo de 2014. Partimos do pressuposto expresso por Flick (2009) de que os registros produzidos pelas pessoas em diversas situações, oficiais ou não, constituem-se como documentos que, mesmo não tendo sido produzidos para fins de pesquisa, podem ter seus conteúdos investigados. 


\section{Avaliação na Educação Infantil: impactos e discussões}

A partir da década de 90, diversos documentos em âmbito federal vêm delineando a Educação Infantil no Brasil ${ }^{1}$. Neste trabalho, nossa opção foi balizar as discussões a partir das indicações das Diretrizes Curriculares Nacionais para Educação Infantil - DCNEI (2010), as quais foram instituídas pela Resolução no . 05/2009 (CEB/CNE). Em relação à avaliação, a referida resolução propõe em seu Art.10 que: "As instituições de Educação Infantil devem criar procedimentos para acompanhamento do trabalho pedagógico e para avaliação do desenvolvimento das crianças, sem objetivo de seleção, promoção ou classificação" (BRASIL, Resolução no 05/2009, p.04).

Nas DCNEI (2010), a avaliação é considerada como parte da proposta de organização curricular, sendo definida como uma forma de acompanhar tanto o professor e sua prática, quanto a criança e seu desempenho. Isto, sob uma perspectiva integral da criança, sem fragmentar o processo avaliativo em áreas do conhecimento. Desse modo, a avaliação não se configura como processo seletivo que promove, classifica ou retém, pois, segundo as novas Diretrizes Curriculares Nacionais para a Educação Infantil, o processo avaliativo deve se constituir com:

\footnotetext{
- A observação crítica e criativa das atividades, das brincadeiras e interações das crianças no cotidiano;

- Utilização de múltiplos registros realizados por adultos e crianças (relatórios, fotografias, desenhos, álbuns etc.);

- A continuidade dos processos de aprendizagens por meio da criação de estratégias adequadas aos diferentes momentos de transição vividos pela criança (transição casa/instituição de Educação Infantil, transições no interior da instituição, transição creche/pré-escola e transição pré-escola/Ensino Fundamental);

- Documentação específica que permita às famílias conhecer o trabalho da instituição junto às crianças e os processos de desenvolvimento e aprendizagem da criança na Educação Infantil;

- A não retenção das crianças na Educação Infantil. (BRASIL, DCNEI, 2010, p. 29).
}

Seguindo as orientações das DCNEI citadas no excerto anterior, as avaliações na Educação Infantil buscam dar visibilidade às diferentes construções de desenvolvimento e aprendizagem das crianças nas rotinas vividas na escola e às formas como essas construções vão se constituindo a partir de uma prática proposta pelo professor.

No cenário educacional brasileiro, além das discussões sobre avaliação das crianças na Educação Infantil, questões que envolvem avaliação externa desta etapa vêm recebendo destaque, mais intensamente, a partir de 2010. Um dos pontos culminantes desse debate é o projeto piloto realizado no ano de 2011, em escolas de Educação Infantil da rede municipal do Rio de Janeiro, onde foi aplicado o teste psicológico norte americano "Ages and Stages Questionnaires - Third Edition" (ASQ-3) ${ }^{2}$ em crianças de 0 a 5 anos de idade.

Em 2012 foi produzido o documento "Educação Infantil: Subsídios para construção de uma sistemática de avaliação" pelo Grupo de Trabalho instituído através da Portaria no

\footnotetext{
1 Dentre os documentos disponibilizados na página do MEC, destacamos: Indicadores da Qualidade na Educação Infantil (2009), Política de Educação Infantil no Brasil: Relatório de Avaliação (2009); Parâmetros Básicos de Infraestrutura para Instituições de Educação Infantil (2009); Parâmetros Nacionais de Qualidade para a Educação Infantil (2006).

2 Informações sobre o teste podem ser obtidas no site < http://agesandstages.com/products-services/asq3>. Acesso em: 10 maio 2016.
}

Práxis Educativa, Ponta Grossa, p. 832-849, v. 11, n. 3, set./dez. 2016 Disponível em: <http://www.revistas2.uepg.br/index.php/praxiseducativa> 
1.147/2011 3 , do Ministério da Educação, com o intuito de “[...] subsidiar a inclusão da educação infantil nas formulações sobre a Política Nacional de Avaliação da Educação Básica, considerando as especificidades da educação na faixa etária de até 5 anos de idade" (BRASIL, 2012, p. 03). Nesse documento consta que foram realizadas manifestações de repúdio à aplicação ao ASQ-3, ou seja:

\begin{abstract}
Vários documentos, expedidos por instituições, especialistas e pesquisadores, foram encaminhados ao Ministério da Educação e divulgados em redes sociais, em sites e blog contrários à aplicação do ASQ-3 e rejeitando sua adoção como instrumento geral de avaliação do desenvolvimento infantil na rede de estabelecimentos educacionais. (BRASIL, 2012, p. 9).
\end{abstract}

A posição da Coordenação Geral de Educação Infantil (COEDI) ${ }^{4}$ é de que a aquisição do ASQ-3 pelo MEC não é adequada, uma vez que a concepção de criança disposta nas DCNEI (2010) vai em direção contrária da apresentada nesse modelo de teste de avalição. De acordo com Garms e Santos (2014, p. 129):

[...] O dilema e o debate estão vigentes. De um lado, profissionais da educação infantil defendem a não aplicação de testes padronizados, homogeneizados para todas as crianças, com propósito de delimitar a etapa ou nível de desenvolvimento e aquisição de objetivos predeterminados para cada faixa etária. Outros profissionais argumentam a favor da obtenção de dados por meio destes testes, questionários ou roteiros de observação por serem eficientes na precisão dos resultados e seguros para planejamento de atividades, seleção de estímulos pontuais para superação do não alcance dos objetivos propostos.

Outra crítica ao teste é levantada por Neves e Moro (2013) no que tange a sua aplicação. As referidas autoras problematizam o fato de o manual de uso do ASQ-3, divulgado pela Secretaria Municipal de Educação do Rio de Janeiro, afirmar que não é necessário ter formação específica para conduzir o teste. As autoras citam a Lei $n^{\circ}$ 4119/1962 a qual determina que o uso deste tipo de teste deve ser realizado somente por psicólogos afirmando que "[...] a aplicação do ASQ e de demais instrumentos dessa natureza por outros profissionais contraria o estabelecido pela legislação específica" (NEVES; MORO, 2013, p. 277).

Com relação à avaliação na Educação Infantil, a legislação brasileiradetermina que esta aconteça: "[...] mediante acompanhamento e registro do desenvolvimento das crianças, sem o objetivo de promoção, mesmo para o acesso ao ensino fundamental [...]" (Lei no 12.796, de 2013, artigo 31, inciso I).

Contudo, o campo de estudos que envolve a avaliação é bastante complexo e não há uma única definição a ser seguida. Desse modo, na próxima seção apresentamos algumas perspectivas que pautaram nossas análises sobre avaliação na Educação Infantil nesta pesquisa.

\footnotetext{
${ }^{3}$ Grupo de Trabalho formado por representantes do Instituto Nacional de Estudos e Pesquisas Educacionais Anísio Teixeira - INEP; da Secretaria de Educação Básica do Ministério da Educação- SEB; do Fundo Nacional de Desenvolvimento da Educação - FNDE; da União Nacional dos Dirigentes Municipais de Educação- UNDIME; da Confederação Nacional dos Trabalhadores em Educação- CNTE; da Associação Nacional de Pós-Graduação e Pesquisa em Educação - ANPED; do Movimento Inter fóruns de Educação Infantil do Brasil- MIEIB e da Rede Nacional Primeira Infância- RNPI.
}

${ }^{4}$ O COEDI é coordenado, desde 2007, pela socióloga Rita de Cássia de Freitas Coelho. 


\section{Perspectivas teóricas sobre avaliação na Educação Infantil}

O termo "avaliação", em sua etimologia, está vinculado ao ato de avaliar, "de dar valor a", de classificar qualitativa ou quantitativamente, de rotular de forma positiva ou negativa algo, alguém ou alguma ação. De acordo com o dicionário Houaiss (2004, p. 79), avaliar significa: "Determinar o valor, o preço, a importância de alguma coisa".

Este termo, nem sempre atendendo a concepção de "dar valor a", está também, diretamente ligado, seja pelo senso comum, seja por teorias e estudos, à escola e aos processos de educação. Para Antunes (2002, p.18), "Não há porque avaliar quando não existe razão do ensinar" e, como a escola é instituída socialmente como local formal de ensino, a avaliação acaba fazendo parte de sua realidade, conforme afirma Hoffmann (2003, p. 58):

Da educação infantil à universidade, crianças e jovens são constantemente sentenciados por seus comportamentos e tarefas. Formal ou informalmente, cada vez que a criança brinca, fala, responde ou faz tarefas está sendo observada e julgada por seus professores. A isto denomina-se avaliação. Esta concepção abrange as ações de observação e julgamento e perigosamente limita-se a elas.

Desse modo, o termo "avaliação" acaba sendo utilizado para nomear, muitas vezes, ferramentas de retenção, promoção, acompanhamento ou classificação. Esta forma de conceber a avaliação, conhecida como avaliação classificatória, geralmente está presente na educação escolar, aplicada aos alunos, representando a visão da escola e do professor que a desenvolve.

Tradicionalmente, no contexto educacional brasileiro, é forte a ideia (e a prática) de que a avaliação se constitui como forma de classificar os alunos de acordo com os saberes que demonstram sobre um assunto em determinado momento ou sobre o alcance deste aluno, mediante os objetivos pré-estabelecidos pelo professor. A compreensão de "avaliação classificatória" vai ao encontro da perspectiva de Esteban (2004, p. 15) ao afirmar que "A avaliação classificatória configura-se com as ideias de mérito, julgamento, punição e recompensa, exigindo o distanciamento entre os sujeitos que se entrelaçam nas práticas cotidianas".

Opondo-se a esta avaliação classificatória, temos a proposta de uma avaliação que acompanha professor e aluno, aproximando-os. Esteban (2004, p. 24) denomina este tipo de avaliação como "prática de investigação" que "[...] tem o sentido de romper as barreiras entre os participantes do processo ensino/aprendizagem e entre os conhecimentos presentes no contexto escolar”. Mesmo que avaliar implique, de alguma forma, em medir, a avaliação precisa ser muito mais ampla que a medida ou a quantificação, pois ela não é um processo em si, mas faz parte de um processo muito maior, que é o da aprendizagem, do ensino e do contexto de oferta, e isso desde a Educação Infantil.

Partindo da ideia que existem diferentes formas de conceber a avaliação na Educação Infantil, Barbosa (2008) identifica duas tradições relativas à avaliação nessa etapa, que vêm se configurando como a realidade desse processo na educação brasileira, nas últimas décadas. Uma delas, objetiva e taxativa e a outra, subjetivista e descritiva. A primeira iniciou entre 1960 e 1970 pautada nos objetivos e nos resultados da psicologia do desenvolvimento,

[...] tendo como parâmetros uma criança idealizada e tida como capaz de realizar determinadas atividades, desenvolver habilidades e evidenciar competências. Obviamente essa criança modelo pertencia, no mínimo, às camadas médias da sociedade. (BARBOSA, 2008, p. 98).

Esse modelo de avaliação, que classifica crianças, ainda está presente nas instituições de Educação Infantil, pois, de acordo com Hoffman (2012), embora não contando com notas ou 
retenções, é comum encontrar nas instituições de educação de crianças de 0 a 5 anos, modelos adaptados de testes e fichas de avaliação que são utilizados no Ensino Fundamental, sem que haja alterações reais na forma de considerar a criança e seu desenvolvimento.

A segunda forma de avaliação citada por Barbosa (2008), bastante presente na Educação Infantil atual, tem caráter subjetivista e propõe um acompanhamento da criança. Essa forma surgiu a partir da década de 1980, como reflexo, entre outros motivos, da democracia que se instaurava no país e das novas perspectivas sobre o desenvolvimento, que consideram a bagagem genética, social e histórica de cada um, ou seja, que percebe o indivíduo e sua história singularmente. "A avaliação com caráter mais subjetivista, foi sendo estruturada a partir da proposta dos pareceres descritivos ou relatórios avaliativos” (BARBOSA, 2008, p. 98).

Esses pareceres tinham como proposta inicial descrever os caminhos percorridos pelas crianças na Educação Infantil, narrando suas ações e reações perante as propostas e oportunidades que lhes eram dadas. Eles visavam diferenciar-se das fichas avaliativas, nas quais tachava-se de "bom" ou "ruim" algum comportamento ou habilidade, por meio de relato detalhado, demonstrando o que vinha sendo feito para incentivar ou transformar essas manifestações das crianças. Mas, muitas vezes, esses pareceres acabavam por se tornar uma "tradução por extenso" das fichas avaliativas. Conforme indica Barbosa (2008, p. 98):

[...] a avaliação compartimentada em tópicos nos quais se marcava com um " $\mathrm{X}$ " $\mathrm{O}$ desempenho do aluno transformava-se em um texto denominado parecer descritivo. Muitos desses instrumentos eram elaborados a partir de observações esporádicas e fragmentadas das crianças, fixando-se características identitárias que poderiam ser flexíveis.

Cabe destacar, que não é possível generalizar e afirmar que esta é a realidade de todos os pareceres e relatórios, mas, conforme o excerto acima citado, muitos se constituem dessa forma, contrariando ao que está expresso na lei e nos documentos oficiais. Nessa perspectiva, as avaliações considerariam, então, as construções feitas pelas crianças e as formas como elas ocorreram, analisando também o professor e sua prática. A partir disso, a avaliação deixa de ser voltada exclusivamente para a criança, ampliando para a prática docente, a qual precisa ser constantemente repensada e reavaliada.

Para tanto, é necessário além do olhar observador do professor, a compreensão de que uma única e pontual forma de avaliar, não abrange as diferentes construções de aprendizagem vivenciadas por cada criança de uma sala de aula. A concepção de avaliação que se dá a partir da observação das crianças considerando seus interesses e da reflexão sobre a prática é denominada por Jussara Hoffman (2012) como "avaliação mediadora".

É importante considerar que a avaliação realizada em sala de aula tem uma intencionalidade que varia de acordo com os objetivos do professor e, assim como qualquer outra prática pedagógica, não há neutralidade no processo de avaliação. De acordo com Bondioli (2004, p. 144):

Pode-se avaliar para realizar um ato de autoridade e reafirmar uma posição de poder; pode-se avaliar para demonstrar a própria superioridade e excelência; pode-se avaliar para tomar decisões sensatas; pode-se avaliar para refletir sobre o que foi realizado com a finalidade de realizar hipóteses de melhorias.

A compreensão do professor sobre a avaliação, revelar-se-á na forma como ele a constrói e o que faz a partir dela. Um professor que se propõe a acompanhar o desenvolvimento da criança e a pensar estratégias para auxiliar nesse desenvolvimento precisa estar disposto a 
conhecê-la e a realidade que a envolve. Nesse sentido, a avaliação entrelaça-se ao acompanhamento.

Esse acompanhamento da criança por parte do professor exige uma organização e sistematização do trabalho pedagógico que inclua registros realizados de formas diversas (diários, fotos, produções da criança, etc.). "A multiplicidade de instrumentos de registro ajuda no processo de detalhamento e na criação de pontos de vista diferenciados" (BARBOSA, 2008, p. 103). Esses registros partem da observação docente e deveriam refletir tanto na aprendizagem da criança quanto no trabalho do professor. Assim, compreendemos que ao observar e avaliar a criança, o professor analisa também a sua prática.

A partir dos estudos de Hoffmann (2003; 2004; 2012) consideramos que a avaliação é parte do processo de aprendizagem e não corresponde a um momento final realizado por meio de testes, provas, conceitos e classificações, mas sim a um olhar observador, reflexivo e constante sobre o processo.

Da mesma forma, concordamos com Bondioli (2004, p. 146), quando ressalta que:

Se avaliação não é capaz de desencadear um processo de repensar, de renovar, reorganizar, se, se reduz a uma pura prática burocrática, ao desempenho de uma tarefa designada, perde todo seu valor e seu sentido, que é de colocar-se a serviço de um projetar cada vez mais consciente, assumido e passível de renovação.

Em suma, a Educação Infantil requer uma avaliação específica que vise acompanhar a criança, entendendo que o "[...] o acompanhamento das aprendizagens é a única maneira de não valorizar apenas o resultado, mas sim dar valor e visibilidade a todo percurso construído no processo de aprendizagem" (BARBOSA, 2008, p. 103). Esse acompanhamento da criança, construído a partir de registros oriundos da observação docente, possibilita conhecer suas aprendizagens e limitações, e também a reorganização do trabalho docente.

Contudo, retomando a perspectiva de Hadji (2001), consideramos que as concepções dos professores sobre educação, criança, papel docente, aprendizagem, ensino e avaliação são as que efetivamente vão direcionar o processo avaliativo, os instrumentos e as formas de registros a serem escolhidos e a maneira como as relações vão se estabelecer nesse processo.

Na próxima seção, apresentamos os dados da pesquisa que realizamos sobre como uma professora de Escola Municipal - Educação Infantil em Rio Grande (RS) concebe a avaliação das crianças nesta etapa da Educação Básica.

\section{Concepções de avaliação a partir da análise dos relatórios da turma}

A pesquisa que apresentamos neste artigo foi realizada por meio de análise documental Flick (2009), a partir de dezesseis relatórios, dos quais, dois "Relatórios da turma", e quatorze "Relatórios Individuais" de cada criança, produzidos e disponibilizados por uma professora da pré-escola, Nível II, de uma Escola Municipal de Educação Infantil ${ }^{5}$ do município do Rio Grande (RS). Esses documentos são entregues ao final de cada semestre para as famílias como forma de registro da avaliação das crianças realizada pela professora.

\footnotetext{
${ }^{5} \mathrm{~A}$ orientação da coordenação pedagógica desta escola é de que os registros da avaliação sejam realizados por meio de relatórios coletivos (turma) e individuais (de cada criança). Essa informação foi obtida por meio de relato da professora no momento de coleta dos relatórios.
}

Práxis Educativa, Ponta Grossa, p. 832-849, v. 11, n. 3, set./dez. 2016 Disponível em: <http://www.revistas2.uepg.br/index.php/praxiseducativa> 
Entendemos que estes registros produzidos pela professora, são, segundo Bogdan e Biklen (1994), documentos oficiais e que, no caso de registros sobre os alunos, revelam também dados sobre quem os produz (o professor) e não sobre a perspectiva da criança. Conforme os referidos autores, "Nesses documentos os investigadores podem ter acesso à "perspectiva oficial", bem como às várias maneiras como o pessoal da escola comunica" (BOGDAN; BIKLEN, 1994, p. 180).

Os relatórios, tanto da turma, como os individuais, compõe o corpus de análise desta pesquisa, cujo objetivo é compreender o que eles revelam sobre a avaliação, as concepções da professora sobre esse processo e a participação das crianças e das famílias. Para análise, esses materiais foram lidos inúmeras vezes e reorganizados em eixos criados a partir de agrupamentos de frases ou parágrafos, os quais correspondiam ao mesmo enfoque. Somente após exaustivos arranjos e rearranjos de excertos que expressavam as mesmas abordagens, é que conseguimos chegar às configurações aqui apresentadas.

Uma das primeiras especificidades que percebemos é que a escrita dos "Relatórios da turma", narram na primeira pessoa do plural (em quase todo texto), as atividades e projetos desenvolvidos. Os "Relatórios Individuais" são referentes a cada uma das sete crianças da turma, sendo que cada criança tem dois relatórios, um para cada semestre de 2014.

Com relação ao campo textual, notamos que os dois "Relatórios da turma", do $1^{\circ}$ e do $2^{\circ}$ semestre, apresentam uma linguagem que em alguns trechos pode ser considerada como coloquial, por conter termos no diminutivo e algumas expressões oriundas da fala, sendo redigidos em um texto coerente, coeso e claro. Acreditamos que os interlocutores a quem estes relatórios se direcionaram (pais ou responsáveis), devem tê-los compreendido facilmente, visto que a linguagem é bastante acessível e a escrita clara. De acordo com Garms e Santos (2014, p. 139):

A comunicação da avaliação é essencial no processo de ensino-aprendizagem. Qualquer que seja a avaliação, essa deverá ser comunicada aos pais, alunos e escola e em diferentes linguagens. Para os pais deve ser clara e compreensível, ou seja, simples e breve.

O relatório do primeiro semestre inicia com um parágrafo que faz alusão às expectativas que comumente são detectadas em qualquer início de ano letivo, e não especificamente às que foram vivenciadas pela professora ou pela turma. Essa escrita introdutória demonstra, de certo modo, uma visão que generaliza as crianças e as turmas de Educação Infantil, desconsiderando que cada grupo de crianças é único e que: "Toda avaliação pedagógica incide sobre o aluno. Mas, se importa avaliar o desenvolvimento e aprendizagem de cada criança, um grupo não é um somatório de indivíduos" (SILVA, 2014, p. 158).

Depois da introdução, o foco do texto é a descrição das atividades e dos projetos, bem como das aprendizagens da turma, na ordem cronológica em que ocorreram. Como por exemplo:

Encantados com a lagarta que apareceu na escola, fizemos diversas pesquisas sobre as transformações sofridas pelas lagartas e tudo que envolvia esse bichinho tão encantador. Desde seu nascimento até a metamorfose e sua transformação em borboleta. Com essas aprendizagens recebemos de presente a letra L para compor nosso alfabeto. (Relatório da Turma, 2014).

Este é um relato que revela uma avaliação e descrição do que foi proposto e realizado, mas não narra como foi recebida e vivenciada a proposta pelas crianças, como ocorreu de fato e como afetou a turma. Segundo Silva (2014, p. 158): 
A avaliação do grupo incide fundamentalmente na observação e no registro das suas características como ambiente de desenvolvimento e aprendizagem, tais como clima relacional existente (se as crianças se sentem acolhidas, se as duas iniciativas são incentivadas, respeitadas e estimuladas), o modo como se processam as interações no grupo (entre pares e entre adultos e crianças) e, ainda, a forma do seu funcionamento (estabelecimento de rotinas e de regras) que permite que o grupo se constitua como um ambiente de aprendizagem para cada uma e todas as crianças.

O texto é quase todo escrito em primeira pessoa do plural, no qual se percebe a intencionalidade de indicar que a autoria é coletiva, incluindo as crianças e a professora: "Nossas vivências começaram integrando duas turminhas em uma só [...] Fizemos um bolo colorido, pintamos nosso baú com as cores do arco-íris e recebemos de presente [...]". (Relatório da Turma, 2014 - grifo nosso).

Porém, em um único parágrafo deste relatório, identificamos que a professora modifica o foco narrativo, assumindo sozinha a autoria do texto para revelar o que uma determinada ação proporcionou às crianças. A possibilidade de mudança na voz verbal pode se justificar na percepção do adulto sobre a criança, o que notamos quando a professora escreve:

Esse projeto proporcionou às crianças autonomia e certa organização, pois todos se
tornaram mais independentes na hora de organizar seu material no espaço
determinado para eles, de encontrar a cadeirinha com seu nome, de fazer a
chamada, reconhecendo o nome de todos os colegas e, também, de colocar seu
nome em todas as atividades que realizam. (Relatório da Turma, 2014 - grifo
nosso).

Essa percepção das aprendizagens desenvolvidas pelas crianças a partir de uma determinada ação provém do olhar observador da professora e revela, pela mudança da pessoa verbal, a possibilidade de que estas aprendizagens não tenham sido percebidas efetivamente pelas crianças, apesar de terem ocorrido com elas. É importante ressaltar que a observação como instrumento da avaliação, pode ir além do mecânico, cujo objetivo é a elaboração de registros com fins burocráticos. A observação alicerçada no acompanhamento das crianças, da proposta pedagógica e na reflexão crítica possibilita identificar avanços, retrocessos, dificuldades e motiva a pensar em estratégias mais interessantes e desafiadoras para o grupo e/ou para a criança individualmente. No relato da professora não identificamos uma intervenção explícita por meio do projeto proposto. Ela observa transformações, mas não deixa transparecer em sua escrita se a intervenção foi planejada e nem como essas mudanças transcorreram. Silva (2014, p. 146) ressalta que:

Sendo a observação das crianças um fundamento essencial da avaliação, essa não pode se basear numa observação informal, exigindo um processo intencional e sistemático, que implica registros que possam ser posteriormente analisados, interpretados e refletidos.

Por meio do "Relatório da turma", é possível afirmar que a professora revela o acompanhamento e observação do que foi proposto, ou seja, das atividades planejadas por ela, sendo que a forma como elas foram efetivamente vivenciadas pelas crianças e pelo grupo, basicamente não é relatada. Exceção disso, é o trecho que trata da organização e autonomia, citado anteriormente.

A partir da leitura do relatório do primeiro semestre é possível elencar que: a professora trabalha por projetos, há propostas lúdicas, o interesse das crianças é levado em consideração, a pesquisa faz parte de suas aulas, o trabalho está voltado para letras do alfabeto de forma contextualizada e significativa para as crianças (de acordo com o que está escrito). Tendo em vista

Práxis Educativa, Ponta Grossa, p. 832-849, v. 11, n. 3, set./dez. 2016 Disponível em: <http://www.revistas2.uepg.br/index.php/praxiseducativa> 
que o relatório do segundo semestre segue a mesma organização e características do primeiro, passamos para a análise dos relatórios individuais.

\section{Relatórios individuais como expressão da concepção de avaliação}

Junto ao "Relatório da turma", é entregue a cada família, ao final de cada semestre, um relatório individual da criança ${ }^{6}$. Nessa escola, a família é bimestralmente informada através de reuniões, sobre a avaliação, tendo acesso semestral a documentos que registram essa avaliação. De acordo com Garms e Santos (2014, p. 139), "Compartilhar a avaliação com a família é condição essencial para que a escola possa ter um conhecimento mais completo e global de seu filho $[\ldots] "$.

Identificamos que todos os relatórios individuais do primeiro semestre apresentam praticamente a mesma estrutura e organização textual, contendo cabeçalho, tendo entre uma página e meia e duas páginas e uma sequência de escrita semelhante. Na escrita, a professora assume o papel de "narradora observadora", descrevendo comportamentos e ações, de forma ampla, com poucos exemplos específicos, mapeando de maneira geral as ações das crianças e suas habilidades e competências.

A partir da análise do conjunto de relatórios individuais, elencamos nove eixos temáticos que se fizeram presentes na escrita, sendo que sete deles compreendem o que denominamos de "Habilidades, competências e aprendizagens". Estes sete eixos assemelham-se a um roteiro que se repete na escrita de cada relato, inclusive são dispostos na mesma ordem em todos os relatórios. Os outros dois eixos, são "Intervenção da professora" e ainda, "Descrição de fatos" que está presente em apenas um relatório.

Os sete eixos comuns a todos relatórios individuais foram por nós nomeados como: i) Aprendizagem e projetos da turma; ii) Comportamento social; iii) Corporeidade e Movimento; iv) Motricidade, v) Desenho e pintura; vi) Oralidade e raciocínio lógico; vii) Alfabetização e conceitos matemáticos.

O primeiro dos sete eixos elencados, "Aprendizagem e projetos da turma", constitui-se de uma exposição do que foi aprendido pela turma no primeiro semestre e uma breve explicação sobre o projeto que vem sendo desenvolvido. Este eixo consiste no parágrafo introdutório dos relatórios e repete-se sem alterações em todos eles. O excerto a seguir ilustra esse aspecto:

Durante o decorrer do $1^{\circ}$ Semestre nossa turma, do Nível II - A, aprendeu a escrever e reconhecer o nome próprio, como também a reconhecer o nome dos colegas. Além das aprendizagens sobre os nomes e a identidade de cada um, estamos desenvolvendo nosso projeto sobre as histórias do Sr. Alfabeto, projeto este que se baseia nos interesses das crianças, interesses que já surgiram e que ainda vão surgir ao longo do ano. (Relatório Individual, 2014).

A primeira frase escrita pela professora afirma que a turma aprendeu algo (escrever e reconhecer seu nome e o dos colegas), assim compreendemos que todos haviam conseguido construir essa aprendizagem, visto que o termo "turma" subentende todas as crianças que dela fazem parte. Porém, ao longo da leitura identificamos alguns trechos que contradizem o que foi exposto inicialmente, por exemplo: "Ainda não consegue escrever seu nome sozinho, mas reconhece-o e tem vontade de escrevê-lo, mas não se desafia a escrever sozinho" (Relatório

\footnotetext{
${ }^{6}$ A identificação dos relatórios segue a numeração de 1 a 7 de acordo com a ordem alfabética do nome de cada criança a fim de não revelar sua identidade.
} 
Individual, Criança 02, 2014), "Está aprendendo a escrever seu nome sozinha, por enquanto, ainda precisa da ajuda da professora para lembrar-se de todas as letrinhas" (Relatório Individual, Criança 06, 2014) e ainda confirmando o que ela apontou "Desde o início do ano consegue escrever seu nome sozinho, mas a cada dia se esforça para que as letrinhas fiquem mais alinhadas” (Relatório Individual, Criança 01, 2014).

É possível que esta contradição demonstre que a forma como a professora percebe as crianças na turma, distingue-se da forma como ela as percebe individualmente. Ou seja, a professora afirma que o grupo aprendeu, mas duas crianças não aprenderam efetivamente. Essa constatação demonstra que ao pensar na aprendizagem do grupo, é considerado o que a maioria aprendeu, ficando subsumido nessa generalização os processos dos que não aprenderam.

O segundo eixo que percebemos em todos os relatos, foi o "Comportamento social". Ele se refere à postura da criança como aluno, como colega, suas ações, reações e personalidade. A interação da criança com os outros, com a professora e com as propostas da aula são pontuadas nestes trechos.

Este eixo é o mais extenso dentro do texto, ocupando cerca de cinco parágrafos em cada relatório. Seguindo praticamente a mesma ordem nos quatorze relatórios, ele agrega os seguintes tópicos: participação e interesse nas aulas, interação com adultos e crianças, respeito e compreensão de regras, problemas comportamentais, postura diante de conflitos, novidades e desafios. A extensão deste eixo revela a importância, para esta professora, que as relações e interações e, principalmente as atitudes e reações das crianças têm na avaliação. Narrar como as crianças têm se portado e quais são suas características é o que mais se destaca no relatório individual.

Sobre esse aspecto, Hoffmann (2003) discute o risco das questões comportamentais e socioafetivas serem privilegiadas nos relatórios elaborados pelas professoras. O problema estaria vinculado ao esquecimento dos aspectos cognitivos devido à preocupação em relatar comportamentos, visto que não há conceitos pré-estabelecidos (como havia nas fichas avaliativas). Ou seja, "O professor que anota apenas o comportamento infantil não terá elementos para abordar seu desenvolvimento" (GUIMARÃES; OLIVEIRA, 2014, p. 286).

Cabe destacar que as interações e as brincadeiras são, segundo as DCNEI (2010), os eixos que devem embasar as propostas na Educação Infantil, contudo, nos relatórios analisados percebemos que os aspectos sociais e comportamentais das crianças ganham destaque, como por exemplo no trecho a seguir: "[...] tem um ótimo relacionamento com todos os seus colegas, sempre procura entender cada um e não gosta de vê-los brigando. É o reconciliador da turma e não se importa de ajudar seus colegas" (Relatório Individual, Criança 01, 2014). Foi possível perceber que a professora contempla aspectos cognitivos nos relatórios, mas nenhum deles é tão detalhado como os aspectos comportamentais.

Um outro fato que merece destaque é a escolha dos adjetivos que caracterizam as crianças, como "carinhoso", "amigo" e "dinâmico", que são postos de maneira pontual e não se respaldam em nenhuma descrição de ações que os ilustrem. A narrativa sobre as relações é bastante ampla, palavras generalistas definem um comportamento, deixando a cargo do leitor a compreensão ou definição de "ótimo", por exemplo. Se a criança tem um "ótimo" relacionamento com os colegas, pode se subentender que lidera o grupo positivamente ou que não briga com ninguém ou, se briga, sabe desculpar-se ou, que é querida e aceita por todos ou sabe lidar com a não aceitação e ainda uma infinidade de possibilidades que podem ser contempladas pelo termo "ótimo". 
O uso destes termos classificatórios tende a traduzir em texto, uma ficha de avaliação, que apresenta categorias as quais "encaixam" um comportamento da criança em um padrão, sendo considerado ótimo aquele que mais se aproxima do padrão estabelecido. No trecho que revela como a criança se relaciona com as demais, observamos um exemplo desta situação, o qual está disposto da mesma forma em cinco relatórios: "É carinhoso e mantém uma ótima relação com todos ao seu redor" (Relatório Individual, Crianças 01, 02, 03, 04 e 07, 2014).

Como foi possível perceber, uma mesma frase caracteriza a forma como cinco crianças estabelecem relações entre si. Contudo, por se tratar de pessoas com histórias e famílias diferentes umas das outras, supomos que haja diferenças também na forma como se relacionam uns com os outros. Porém, o relatório classifica todos como "ótimo" ficando subentendido que para este termo pode haver mais de uma interpretação.

Identificamos também que as dificuldades comportamentais encontradas pelas crianças não são postas desta forma generalista, como os eixos citados anteriormente. A professora relata algo específico de cada uma e a forma como a criança tem administrado isso, conforme é possível identificar nos seguintes excertos: "Ainda tem um pouquinho de dificuldade para lidar com a frustração, não gosta de perder, mas tem se esforçado para compreender que podemos ganhar ou perder, que tudo é aprendizado". (Relatório Individual - Criança 01, 2014); “[...] tem tido algumas dificuldades para lidar com os outros adultos da escola. Quer atenção da professora a todo momento e não aceita que outro adulto lhe dê essa atenção". (Relatório Individual - Criança 03, 2014). Todos os relatórios apontam uma situação-problema relativa ao comportamento da criança que precisa ser ou está sendo desenvolvida.

A postura assumida pela criança diante de desafios é expressa no mesmo parágrafo que aborda o eixo "Corporeidade e movimento", estando, em alguns relatos, ligada a este eixo, vinculando o desafio às atividades corporais. Percebemos que a escrita que contempla o eixo "Corporeidade e movimento" é o menor, variando entre uma e duas frases. Estas frases são seguidas de apontamentos sobre como a criança lida com desafios. A base deste eixo é pontuar se a criança tem ou não domínio do seu próprio corpo, porém como isto é percebido e a compreensão do termo "domínio", são processos que não estão descritos.

Pelo que foi possível analisar, podemos considerar que o relatório individual contempla somente o registro do que a observação revela de maneira pontual, sem considerar o percurso, a forma como acontece e os reflexos disto, tanto para criança, quanto para o trabalho do professor. Sob a perspectiva de avaliação mediadora, temos um relatório que abrange uma pequena parte do processo, não podendo ser percebido como registro da "avaliação", visto que:

[...] não se pode denominar de "avaliação" apenas a observação e o registro. Isto é, o processo avaliativo envolve necessariamente a reflexão crítica sobre o que se observou e a ação pedagógica decorrente de apoio ao aprendiz, sendo esta a finalidade da avaliação mediadora. (HOFFMANN, 2014, p. 251).

Para encerrar a escrita dos relatórios, a professora retoma o eixo "Comportamento social”, caracterizando e definindo cada criança (postura e preferências). No início do parágrafo, as crianças são descritas através da frase: "É um (a) menino (a) muito esperto que está sempre se esforçando para aprender tudo que ensinamos [...]” (Relatório Individual, 2014).

O que modifica em uma das frases analisadas é o adjetivo, que ora é "interessado", ora "participativo" ou, ainda, "quietinho", os quais aparecem ao lado de "esperto", sendo que o restante da frase é comum a todos os relatos. Consideramos que a escrita apresentada nos relatórios tende a uma padronização das crianças, de suas ações relativas à aprendizagem e de seus comportamentos. Todas são descritas como espertas e esforçadas, e não há referência sobre 
como isto foi percebido ou demonstrado. Deste modo, as particularidades de cada criança não são consideradas nos relatórios, uma vez que todas podem ser descritas por meio da mesma frase.

Os eixos que denominamos como "Motricidade" e "Desenho e pintura" estendem-se em cerca de um parágrafo e expõe se a criança desenha com detalhes, pinta respeitando limites e usando cores variadas e, nos dois casos, se sabe utilizar o lápis com segurança. A descrição é bastante pontual, contendo trechos que expressam o questionamento de alguém para as crianças sobre a escolha das cores, sendo que pressupomos que este "alguém" é a professora.

O eixo "Oralidade e raciocínio lógico" inicia, em quase todos relatórios, descrevendo se a criança consegue explicar o que desenhou, se tem interesse por histórias (ouvir e contar) recontando-as ou criando-as com lógica, se expressa-se com clareza e, em dois casos trata sobre o tom de voz da criança, categorizando um como "muito alto" e outro como "adequado para a idade". Esta categorização revela que a professora percebe que há um padrão adequado para o tom de voz de crianças nessa idade e que uma das crianças não se aproxima desse padrão.

No último eixo que identificamos como "Alfabetização, letramento e conceitos matemáticos", a professora aponta a capacidade de escrita e reconhecimento do nome, identificação do nome dos colegas e das letras do alfabeto, se consegue contar até 10 e se relaciona números e quantidade. A escrita da professora indica se a criança "consegue" ou "está aprendendo" qualquer uma destas ações. E todos os relatórios encerram com uma frase sobre o envolvimento da criança no processo de letramento: "É uma criança que se demonstra completamente envolvida pelo processo de letramento" (Crianças 01, 02, 04 e 05, 2014); "É uma criança que se demonstra bem envolvida pelo processo de letramento" (Crianças 03 e 07 Relatório, 2014); “[...] não demonstra muito interesse pelo processo de letramento" (Criança 06, 2014).

Ao observar estes trechos, refletimos sobre qual seria a concepção de letramento da professora e como este termo seria compreendido pelos pais, visto que é um termo que se relaciona à alfabetização, mas que tem definições complexas e exige conhecimento específico para ser compreendido. No caso dos pareceres analisados não há indícios suficientes que nos permitam fazer afirmações sobre a perspectiva de letramento da professora. Considerar que a escrita do nome, o reconhecimento do alfabeto e do nome dos colegas revelam a concepção de letramento, seria uma conclusão aligeirada, precipitada e sem dados que a justifique. Contudo, entendemos que alguns termos passam a ser incorporados na escrita sem uma maior problematização e definição acerca do que está sendo entendido por eles.

Em relação às ações mediadoras, consideramos que essas estão pouco presentes e são brevemente expostas no eixo "Intervenção da professora" que corresponde às ações assumidas pela professora para auxiliar uma criança. Interessante destacar que sempre que este eixo aparece, a professora passa a narrativa para o sujeito "nós". Ao perceber dificuldades (sejam emocionais, sociais ou cognitivas) nas crianças, em um processo avaliativo mediador, a professora tem a possibilidade de refletir sobre sua prática, avaliar se esta tem proporcionado situações que auxiliem na superação das dificuldades e reorganizá-la. Estas ações exigem o ciclo de observação, reflexão e planejamento (posto em prática), no qual a necessidade de intervenção é percebida na observação, articulada na reflexão e efetivada na ação pedagógica, "[...] o olhar avaliativo deve abarcar as singularidades dos educandos para que as estratégias pedagógicas se ajustem a cada um” (HOFFMANN, 2011, p. 16).

A maior incidência das intervenções percebidas nos relatórios ocorre junto aos eixos que abordam "postura diante de desafios" e a "interação com o outro". Nestes trechos, ainda que de 
forma breve, é possível notar que a professora costuma intervir junto à criança para incentivá-la e auxiliá-la a resolver problemas de comportamento, conforme observamos nos relatórios do $1^{\circ}$ semestre/2014: "[...] quando ajudamos a resolvê-los ela compreende facilmente que é preciso manter a calma e resolver todas essas situações conflitantes da melhor maneira possível" (Criança 06); "Quando conversamos sobre isso ele revê suas atitudes e compreende a importância de manter a calma em todas as situações conflitantes" (Criança 05); "Sempre que isso acontece conversamos com ela e, logo, logo as coisas começam a se acertar”.

A partir destes excertos observamos que a professora intervém em situações nas quais ela considera que as crianças precisam de ajuda, mas todas as narradas no relatório estão ligadas ao "Comportamento", seja na interação, seja individualmente. Intervenções ligadas ao "cognitivo" não foram identificadas. Uma outra questão que percebemos foi que essas intervenções não partem necessariamente de um planejamento prévio, feito a partir de uma observação, ou seja, não derivam de um processo de avaliação, pois ocorrem em momentos pontuais, quando o problema acontece. Identificamos que o diálogo é a ferramenta principal adotada pela professora na maioria das situações, como forma de intervenção pedagógica e, conforme o exposto no relatório, ele sempre surte o efeito esperado, ao menos no momento em questão.

Embora esta estratégia de intervenção seja a única evidenciada no texto dos relatórios e, abra margem para o entendimento de que ela não é fruto de planejamento, o diálogo entre adultos e crianças destaca-se como uma interação importante e fundamental no contexto educativo. Smith e Craft (2010) ressaltam essa perspectiva quando expõem que:

Ao explorar o diálogo na sala de aula, Wegeriff (2002) sugere que o envolvimento bem
sucedido entre os adultos e crianças pode tanto oferecer quanto desenvolver um
contexto de aprendizagem muito forte em que o pensamento das crianças se
desenvolve tão explicitamente quanto seus interesses. (SMITH; CRAFT, 2010, p. 35).

Emergindo do diálogo entre professor e criança, o último eixo "Descrição de fatos" está presente em apenas um relatório e refere-se a uma breve narrativa sobre a preferência de uma das crianças, sendo ilustrada também por alusões às falas dela, ou seja, "Adora tudo que está relacionado às pescarias que faz com o avô, histórias sobre "traíras" é o que ele mais gosta de contar" (Criança 05). Esse é o único trecho em que, sem ser de forma generalista, como em "participa das aulas, ou, conta histórias" a professora ressalta algo dito pela criança, algo que foi vivido e desejado por ela, além de ser dotado de significado para essa criança.

Para descrever no relatório falas e ações individuais de cada criança, diante de situações diversas, faz-se necessário um olhar atento sobre cada uma delas. Além disso, um exaustivo exercício de registro, por meio de diários, filmagens, fotografias, coleta de documentos produzidos pelas crianças, entre outros, para a constituição de um acervo que permita o acompanhamento do processo vivenciado. De acordo com Silva (2014, p. 146):

\footnotetext{
A necessidade do registro decorre, em primeiro lugar, de um aspecto óbvio, se não se dispuser de registros nomeadamente resultantes de observações, há uma sobreposição de memórias, que vão se diluindo no conjunto de outras não havendo possibilidade de situar esse comportamento ou situação no tempo, de dar conta de uma evolução essencial para conhecer o processo educativo.
}

A ausência de relatos de falas e posturas individualizadas nos relatórios aqui analisados revelam que mesmo a professora tendo um olhar atento ao que se passa em aula cotidianamente (com base na descrição de seus projetos) ela não considera em seus apontamentos as particularidades das crianças, pois não há descrição de situações ou registros de suas falas nos diferentes momentos vivenciados no contexto da Educação Infantil.

Práxis Educativa, Ponta Grossa, p. 832-849, v. 11, n. 3, set./dez. 2016 Disponível em: <http://www.revistas2.uepg.br/index.php/praxiseducativa> 
Tínhamos inicialmente a intenção de identificar de que forma a participação das famílias se dava no processo de avaliação. Contudo, o material analisado não possibilitou que pudéssemos aprofundar essa questão. Podemos afirmar apenas que os pareceres são entregues às famílias em reuniões que ocorrem no final de cada semestre.

Por meio da leitura dos relatórios individuais do primeiro semestre continuamos compreendendo que a concepção de avaliação da professora, expressa em sua escrita, tende a focar-se em resultados, que se embasam em uma classificação e homogeneização das crianças, nos quais há destaque para questões sociais e comportamentais. Os relatórios individuais do segundo semestre revelam a mesma organização do texto dos primeiros relatos. As propostas da professora novamente são introduzidas em todos os relatórios através do mesmo parágrafo. Neles são narrados os projetos e interesses de uma maneira geral, visto que esses temas foram descritos com maiores detalhes no relatório da turma.

O eixo "Comportamento social" está novamente, presente em todos os relatos, ocupando maior número de parágrafos e envolvendo as mesmas questões. A abordagem e a escrita seguem a mesma lógica dos relatos do primeiro semestre, evidenciando comportamentos, sem contextualizá-los ou ilustrá-los, pontuando ações finais, sem narrar sua construção nem demonstrar acompanhamento efetivo das mesmas.

Há um parágrafo final, basicamente igual em todos os relatórios, que se caracteriza como uma despedida da professora e apresenta os desejos que ela "tem e faz" em relação ao futuro das crianças, nas novas turmas e escolas do próximo ano: "Desejo que ele tenha cada dia mais sucesso na sua caminhada e que o $1^{\circ}$ ano seja muito especial assim como foram os anos que convivemos uns com os outros!” (Relatório Individual, Criança 01, $2^{\circ}$ semestre de 2014).

Em alguns trechos, termos como "ainda, continua, mantém, superando..." revelam que a professora observou a continuidade de posturas das crianças ou, percebeu mudanças nas suas ações, entre o primeiro e o segundo semestre, demonstrando que está atenta ao desenvolvimento das crianças, em diversos aspectos, sendo maior sua atenção aos aspectos que correspondem a questões sociais e comportamentais. Contudo, não foi possível identificar nos relatórios analisados, elementos que explicitassem o como e o porquê de estes comportamentos ocorrerem e quais intervenções pedagógicas foram realizadas.

Após realizar a análise dos relatórios do segundo semestre tivemos a impressão de que estes foram elaborados a partir dos relatórios produzidos no primeiro semestre, tanto pela ordem dos temas elencados, quanto pela repetição extremamente semelhante dos termos escolhidos. Essa prática (bastante comum entre muitos professores) acaba sendo desprovida de significado e incompatível com a proposta de "processo avaliativo" que visa ao acompanhamento, sendo mais parecida com uma versão por extenso de fichas avaliativas de tendência classificatória.

Após a análise dos relatórios, é possível considerar que eles não revelam uma perspectiva de avaliação como acompanhamento, visto que tanto as escritas sobre o grupo, quanto as escritas individuais privilegiam os resultados finais, em detrimento do processo desenvolvido, pelas crianças e pela professora. A ausência de detalhes sobre as ações, reações e falas das crianças nos relatórios, nos suscita pensar que a professora não tem a prática do registro diário ou, se tem, não prioriza o registro de detalhes e exemplos, pois sua escrita não apresenta elementos que ilustrem por que uma criança tem "ótimo" relacionamento ou por que outra não está muito envolvida em algo. Outra hipótese que temos, é que a professora, por considerar estes relatórios uma exigência burocrática e uma norma da escola, não vê a necessidade de aprofundá-los e detalhá-los, uma vez que não os considera como parte da proposta pedagógica. Contudo, para fazermos afirmações mais consistentes, seria necessário aprofundar a investigação, com outras estratégias 
metodológicas, tais como entrevista e observações, as quais não foram realizadas nessa etapa da pesquisa.

\section{Considerações finais}

Definir e desenvolver a avaliação no contexto da Educação Infantil é uma tarefa bastante complexa, visto que esta etapa se diferencia das demais etapas da Educação Básica por não ter uma avaliação pautada em notas, por não objetivar e conceber a retenção de níveis e por abranger diversas formas de documentação e registro desta avaliação. Porém, tanto as DCNEI (2010) quanto a legislação (Lei Federal $n^{\circ}$ 12.796/13) preveem uma avaliação como forma de acompanhamento da criança e seu desenvolvimento. Sob este enfoque, a avaliação visa acompanhar a criança, considerando-a no grupo e individualmente, envolvendo a observação e os registros dessa observação, que servem como bases de memória e de (re)planejamento de ações a serem desenvolvidas pelo professor para que as crianças superem dificuldades, aprendam e se desenvolvam e para que se observe novamente seu desempenho.

Neste artigo, apresentamos resultados de uma pesquisa que buscou compreender como uma professora de uma Escola Municipal de Educação Infantil em Rio Grande (RS) concebe a avaliação das crianças nesta etapa da Educação Básica, a partir da análise documental de relatórios produzidos como forma de registro da avaliação das crianças. Procuramos identificar, também, o que os relatórios revelam sobre a avaliação, bem como, as concepções da professora sobre esse processo e a participação das crianças e das famílias.

Entendemos que os relatórios constituem-se em instrumentos de análise que traduzem concepções da professora e podem revelar tanto uma avaliação classificatória, oriunda de uma prática baseada em verificação, quanto uma avaliação mediadora que advém de uma proposta de acompanhar desenvolvimentos e mediar saberes. Ou ainda, uma avaliação classificatória que parece não condizer com a ação docente mediadora e dialógica desenvolvida pelo professor, o que pode indicar "um não saber" desse professor em relação à avaliação (ou seu registro) que passa a ser uma burocratização, muitas vezes, desprovida de sentido.

Conforme indicado no início deste artigo, as reflexões realizadas acerca dos dados da pesquisa seguiram a perspectiva teórica sobre avaliação a partir de Hoffmann (2003; 2004; 2012), Esteban (2004), Bondioli (2004), Barbosa (2008) e Hadji (2001).

Por meio da análise dos relatórios tanto da turma, como das crianças individualmente, identificamos que a professora percebe as crianças dentro do grupo, pela ação da maioria e, individualmente, por suas características mais marcantes e/ou pelas aprendizagens que realizaram ou não. Mesmo que não seja exposta de forma explícita, a ideia de um comportamento infantil padrão e pré-estabelecido é revelado quando uma criança é considerada ótima, outra boa e outra como alguém que ainda não consegue realizar algo esperado. Contudo, o mais inquietante neste aspecto é que os motivos que a levam a estas classificações, e o que tem sido proposto a partir dessas constatações, não são descritos no relatório.

Também não foi possível identificar a partir dos relatórios analisados, de que modo a avaliação contribui para a reestruturação da prática pedagógica, para a qualificação do trabalho realizado na escola e para uma efetiva ação que produza crescimento das crianças e de suas famílias. Da mesma forma, não identificamos na escrita dos relatórios, aspectos que indicassem a participação da família no processo de avaliação.

Práxis Educativa, Ponta Grossa, p. 832-849, v. 11, n. 3, set./dez. 2016 Disponível em: <http://www.revistas2.uepg.br/index.php/praxiseducativa $>$ 
Desse modo, constatamos que os relatórios, tanto da turma como os individuais tendem a ser uma produção pontual, elaborada ao término do semestre e construída com base nas lembranças que a professora tem da turma e da criança ou em alguma anotação menos detalhada e não sistemática. Isso revela, que a avaliação realizada nesta turma não está articulada ao planejamento da prática pedagógica, nem a uma "avaliação mediadora” Hoffman (2012).

O propósito dos relatórios de grupo elaborados pela professora da pré-escola Nível II é contar como as propostas surgem e o que a turma aprendeu com elas. Estes relatórios revelam que a visão de avaliação da professora vincula-se às propostas iniciais e aos resultados sem, contudo, demonstrar reflexões sobre o processo. Não há indícios de reorganização do trabalho docente a partir de uma avaliação processual, que promova a projeção de uma proposta pautada na análise do que vem sendo realizado (BARBOSA, 2008; BONDIOLI, 2004).

Além disso, o foco dos relatos individuais é pontuar o que as crianças conseguem ou ainda não conseguem, aprenderam ou não e como se comportam. Em vários trechos há sinais de uma escrita generalista, que se repete nos relatórios de várias crianças, levando a crer que qualquer uma delas se encaixaria nos relatos.

A partir dos dados da pesquisa, ficou claro que muito se avançou no que tange a avaliação na Educação Infantil, tanto em relação às práticas cotidianas, como nas propostas políticopedagógicas, uma vez que se passou de uma avaliação fragmentada em itens, os quais eram marcados com um " $x$ ", para uma descrição mais elaborada da criança "real". Contudo, faz-se necessário ainda maior investimento em pesquisas que revelem de que formas são realizadas as práticas avaliativas em diferentes escolas de Educação Infantil, bem como maior investimento na formação inicial e continuada de professores para que estas possibilitem efetivos estudos e discussões sobre a especificidade da avaliação na Educação Infantil.

\section{Referências}

ANTUNES, C. Avaliação da aprendizagem escolar. 3. ed. Petrópolis: Vozes, 2002.

BARBOSA, M. C. S. HORN, M. G. S. Projetos pedagógicos na Educação Infantil. Porto Alegre: Artmed, 2008.

BODGAN, R.; BIKLEN, S. Investigação qualitativa em educação. Porto Alegre: LDA, 1994.

BONDIOLI, A. (Org.). O projeto pedagógico da creche e sua avaliação. Campinas: Autores Associados, 2004.

BRASIL. Ministério da Educação. Secretaria de Educação Básica. Diretrizes curriculares nacionais para a educação infantil/Secretaria de Educação Básica. - Brasília: MEC, SEB, 2009.

BRASIL. Ministério da Educação. Política de Educação Infantil no Brasil: Relatório de Avaliação/Secretaria da Educação Básica - Brasília: MEC, 2009.

BRASIL, CEB/CNE. Resolução $\mathbf{n}^{\mathbf{0}}$ 05/2009. Fixa as Diretrizes Curriculares Nacionais para a Educação Infantil em 17 de dezembro de 2009.

BRASIL. Ministério da Educação. Grupo de Trabalho. Educação Infantil: Subsídios para construção de uma sistemática de avaliação/Secretaria de Educação Básica. - Brasília: 2012. 
BRASIL. Lei n. 12.796, de 4 de abril de 2013. Altera a Lei no 9.394, de 20 de dezembro de 1996, que estabelece as diretrizes e bases da educação nacional, para dispor sobre a formação dos profissionais da educação e dar outras providências. Diário Oficial da União, Brasília, 05/04/2013, p. 1.

ESTEBAN, M. T. Ser professora: avaliar e ser avaliada. In: ESTEBAN, M. T. (Org.) Escola, currículo e avaliação. São Paulo: Cortez, 2004. p. 13 -37.

FLICK, U. Introdução à pesquisa qualitativa. Porto Alegre: Artmed, 2009.

GARMS, G.; SANTOS, M. Concepções e práticas de avaliação na Educação Infantil. In: GUIMARÃES, C. M.; CARDONA, M. J.; OLIVEIRA, D. R. de. (Orgs.). Fundamentos e práticas da avaliação na Educação Infantil. Porto Alegre: Mediação. Porto Alegre, 2014. p. 111-126.

GUIMARÃES, C.; CARDONA, M. J.; OLIVEIRA, D. R. de. (Orgs.). Fundamentos e práticas da avaliação na Educação Infantil. Porto Alegre: Mediação, 2014.

HADJI, C. Avaliação desmistificada. Porto Alegre: ARTMED, 2001.

HOFFMANN, J. Avaliação: mito \& desafio: perspectiva construtivista. 32. ed. Porto Alegre: Mediação, 2003.

HOFFMANN, J. Avaliação mediadora: uma prática em construção da pré-escola à universidade. 24. ed. Porto Alegre: Mediação, 2004.

HOFFMANN, J. O jogo do contrário. 7. ed. Porto Alegre: Mediação, 2011.

HOFFMANN, J. Avaliação e Educação Infantil: um olhar sensível e reflexivo sobre a criança. Porto Alegre: Mediação, 2012.

HOFFMANN, J. Avaliação mediadora na Educação Infantil. In: GUIMARÃES, C. M.; CARDONA, M. J.; OLIVEIRA, D. R. de. (Orgs.). Fundamentos e práticas da avaliação na Educação Infantil. Porto Alegre: Mediação, 2014. p. 243-256.

HOUAISS, A.; VILLAR, M. S. Dicionário Houaiss da língua portuguesa. Rio de Janeiro: Objetiva, 2004.

NEVES, V. F. A.; MORO, C. Avaliação na Educação Infantil: um debate necessário. Estudos em Avaliação Educacional, São Paulo, v. 24, n. 55, p. 272-302, abr./ago. 2013. DOI: 10.18222/eae245520132727

SILVA, I. L. Perspectiva e práticas de avaliação em Educação Infantil. In: GUIMARÃES, C. M.; CARDONA, M. J.; OLIVEIRA, D. R. de. (Orgs.). Fundamentos e Práticas da avaliação na Educação Infantil. Porto Alegre: Mediação, 2014. p. 145-162.

SMITH, A. P.; CRAFT, A. O desenvolvimento reflexivo da prática educativa. Porto Alegre: Artmed, 2010. 